\title{
Transdiagnostic Neural Signatures in common Pediatric Psychiatric Disorders: a data-driven meta-analysis of functional neuroimaging studies.
}

Jules R. Dugré, $\mathrm{MSc}^{1,2}$, Simon B. Eickhoff ${ }^{3,4} \&$ Stéphane Potvin, $\mathrm{PhD}^{1,2}$

${ }^{1}$ Research Center of the Institut Universitaire en Santé Mentale de Montréal, Montreal, Canada

${ }^{2}$ Department of Psychiatry and Addictology, Faculty of medicine, University of Montreal, Montreal, Canada

${ }^{3}$ Institute of Neuroscience and Medicine (INM-7), Jülich, Germany.

${ }^{4}$ Institute for Systems Neuroscience, Heinrich Heine University, Düsseldorf, Germany.

\section{Corresponding authors}

Jules Roger Dugré, PhD Candidate \& Stéphane Potvin, PhD;

Research Center of the Institut Universitaire en Santé Mentale de Montréal; 7331 Hochelaga, Montreal, Quebec, Canada; H1N 3V2; Phone: 514-251-4015;

Email: jules.dugre@umontreal.ca / stephane.potvin@umontreal.ca 
medRxiv preprint doi: https://doi.org/10.1101/2021.03.18.21253910; this version posted March 20, 2021. The copyright holder for this preprint (which was not certified by peer review) is the author/funder, who has granted medRxiv a license to display the preprint in perpetuity.

It is made available under a CC-BY-NC 4.0 International license.

\begin{abstract}
BACKGROUND. In the last decades, neuroimaging studies have attempted to unveil the neurobiological markers underlying pediatric psychiatric disorders. However, children diagnosed with such disorders are likely to receive an additional diagnosis in the following years. Yet, the vast majority of neuroimaging studies focus on a single nosological category, which limit our understanding of the shared/specific neural correlates between these disorders. Therefore, we aimed to investigate the transdiagnostic neural signatures through a novel meta-analytical method. METHOD. A data-driven meta-analysis was carried out which grouped similar experiments topographic map together, irrespectively of nosological categories and taskcharacteristics. Then, activation likelihood estimation meta-analysis was performed on each group of experiments to extract spatially convergent brain regions. RESULTS. One hundred forty-seven experiments were retrieved (3199 subjects): 79 attention-deficit/hyperactivity disorder, 32 conduct/oppositional defiant disorder, 14 anxiety disorders, 22 major depressive disorders. Four significant groups of experiments were observed. Functional characterization suggested that these groups of aberrant brain regions may be implicated internally/externally directed processes, attentional control of affect, somato-motor and visual processes. Furthermore, despite that some differences in rates of studies involving major depressive disorders were noticed, nosological categories were evenly distributed between these four sets of regions. Additionally, main effects of task characteristics were observed. CONCLUSIONS. By using a data-driven meta-analytic method, we observed four significant groups of aberrant brain regions that may reflect transdiagnostic neural signature of pediatric psychiatric disorders. Overall, results of this study underscore the importance of studying pediatric psychiatric disorders simultaneously rather than independently.
\end{abstract}

KEYWORDS: conduct disorder; attention-deficit hyperactivity disorder; anxiety disorder; major depressive disorder; meta-analysis; neuroimaging; transdiagnostic. 


\section{INTRODUCTION}

The most prevalent child psychiatric disorders include Attention-deficit/hyperactivity disorder (ADHD), Conduct/Oppositional Defiant Disorder (CD/ODD), anxiety disorders (ANX) and depressive disorders (DEP) and affect approximately 3.4\%, 5.7\%, 6.5\% and $2.6 \%$ of children and adolescents in the world, respectively (1). More importantly, evidence suggest that comorbidity between these pediatric psychiatric disorders is the norm rather than the exception. In fact, children with ADHD, CD/ODD, ANX or DEP are likely to being diagnosed with one of these four disorder as a comorbid condition (2-9). Indeed, comorbidity is reported in $51.6-83 \%$ of cases, whereas between 3 to $25.8 \%$ have received two or more comorbid psychiatric conditions. Although these four diagnostic entities show large comorbidities in children and adolescent, theoretical pathophysiological models that take into account this high level of comorbidity remain largely limited (10).

In the last decade, there has been a growing body of literature suggesting that several genetic (11-15) and environmental risk factors (15-17) which increase the risk for a wide range of psychiatric disorders \& psychopathologies may be non-specific. Likewise, recent meta-analyses of structural and functional magnetic resonance imaging studies have shown that adult psychiatric disorders may share several neurobiological deficits (18-22). For instance, during cognitive control tasks, transdiagnostic neural signatures have been identified, which involve the fronto-insular cortex (FIC), the dorsolateral prefrontal cortex and the dorsal anterior cingulate cortex (dACC) to anterior midcingulate/pre-supplementary motor area (aMCC/pre-SMA) and inferior parietal 
medRxiv preprint doi: https://doi.org/10.1101/2021.03.18.21253910; this version posted March 20, 2021. The copyright holder for this preprint (which was not certified by peer review) is the author/funder, who has granted medRxiv a license to display the preprint in perpetuity.

It is made available under a CC-BY-NC 4.0 International license .

lobule (21). Similarly, adult patients with psychiatric disorders shared prominent deficits in the FIC, amygdala, thalamus and dorso- and ventro-medial PFC during emotion processing tasks (22). Although some differences have been noticed between patients with and without psychotic disorders $(21,22)$, the search for shared/specific neurobiological features is of great interest for our current understanding of the psychophysiological mechanisms underlying psychiatric disorders.

In neuroimaging literature on childhood/adolescent, studies or meta-analyses that aimed to uncover the specific/transdiagnostic neurobiological markers have been scarce. Indeed, a large majority of task-based fMRI studies has focused on a single psychiatric disorder, therefore limiting our ability to identify common/specific neurobiological markers. Additionally, recent transdiagnostic fMRI meta-analyses have excluded disorders which predominantly emerge in childhood/adolescence such as ADHD and CD/ODD $(21,22)$. Nevertheless, past meta-analyses and literature reviews on ADHD (23-28), CD/ODD (29-33). ANX (34-39) and DEP (40-47) appear to show qualitatively similar deficits in the anterior insula, medial and lateral prefrontal cortex, amygdala and anterior to midcingulate cortex. Yet, there is a clear need for meta-analytical evidence of transdiagnostic neural signatures in children and adolescents.

Despite the fact that these results may provide substantial insight for our understanding of transdiagnostic neural signatures, classical meta-analytical approaches are prone to important biases. Indeed, authors' categorization of groups of interest, categorization of fMRI tasks and the choice of task contrast may significantly alter results. In comparison to the classical meta-analytic approach which seeks to identify dysfunctional brain regions in predefined groups of interest, the reverse inference meta- 
medRxiv preprint doi: https://doi.org/10.1101/2021.03.18.21253910; this version posted March 20, 2021. The copyright holder for this preprint

analytical method rather aims to discover groups of interest in a dysfunctional brain region. As such, this novel approach may address the limitations of the classic approach by searching for common/specific neural signatures irrespective of the taskcharacteristics or the nosological categories. To our knowledge, only one study has investigated transdiagnostic features across adult samples through a reverse-inference meta-analytical method. In fact, the authors observed that when examining diagnosis distribution across brain regions, none of the 56 regions (subcortical and cortical) showed a significant effect of diagnosis across whole-brain studies (48). However, selectively examining diagnosis distribution region after region may yield over-optimistic conclusion about their transdiagnostic characteristics. Given that a single region may be implicated in a wide range of cognitive processes, examining transdiagnostic signatures using a region-of-interest method blurs our ability to capture that co-activation topography may actually differ between psychiatric disorders and reflect functional differences in cognitive processes between disorders. To our knowledge, a meta-analysis aiming to examine transdiagnostic (or specific) groups of regions associated with pediatric psychiatric disorders has never been performed.

Here, we carried out a meta-analysis that primarily aimed to identify groups of aberrant brain regions across psychiatric disorders using a data-driven meta-analytical method. Results from past meta-analyses on adult samples $(21,22)$ and disorder-specific meta-analyses and literature reviews (23-41) suggest that transdiagnostic features may be expected in FIC (anterior insula/vlPFC), medial and lateral prefrontal as well as in the dorsal anterior and anterior midcingulate cortex. However, considering that deficits in the amygdala is systematically observed in past meta-analyses on adult $\operatorname{ANX}(35,36)$ and 
DEP (40-47), but less extensively in CD/ODD (29-33) and not found in ADHD (23-28), we hypothesized that the former region would be more closely linked to ANX and DEP than the latter disorders.

\section{METHODS}

\subsection{Identification of included studies}

Our search focused primarily on four diagnostic categories (ADHD, CD/ODD, ANX, DEP) since they all show high comorbidity with each other (2-9). Since meta-analyses and literature reviews on these disorders have been published recently, we extracted data from reference lists of $\operatorname{ANX}(36,37,39)$, DEP (40, 41, 49), CD/ODD (31), ADHD (28). Inclusion criteria were: (1) original manuscript from a peer-reviewed journal, (2) functional MRI studies that included a fMRI task, (3) use of a whole-brain methodology (i.e., studies using region-of-interest were excluded), $(4)<18$ years old participants meeting criteria for at least one of the following pediatric psychiatric disorder: (a) Attention deficit with/or without hyperactivity; (b) Disruptive disorder (Conduct disorder and/or Oppositional Defiant Disorder); (c) Anxiety disorders (i.e., Posttraumatic Stress Disorder, Generalized Anxiety Disorder, Social Anxiety Disorder) and/or (d) Unipolar Major Depressive Disorder.

\subsection{ALE Method}

ALE approach was used in the current coordinate-based meta-analysis in order to extract spatially convergent peaks across pediatric psychiatric disorders (GingerALE version 3.0.2, http://www.brainmap.org/ale/). Study results were extracted, irrespectively 
medRxiv preprint doi: https://doi.org/10.1101/2021.03.18.21253910; this version posted March 20, 2021. The copyright holder for this preprint

of the direction (decreased/increased) of the diagnosis or task-contrast effect, to create an aberrant activation map. Two experiments from the same study were considered as distinct if they included two different samples or two different fMRI tasks. Each experiment' pooled task-contrasts was manually annoted and categorized if they included: a cognitive component (i.e., response inhibition, attentional processes); an emotional component (i.e., response to positive stimuli; to negative stimuli; to both). These categorizations were not mutually exclusive (e.g., emotional go-no/go or Stroop). Rates of boys in each sample and percentage of subjects that received medication were also extracted for each experiment. Coordinates of experiments that were reported originally in Talairach stereotaxic space were converted into MNI (Montreal Neurologic Institute) space before using them in the analyses.

First, a modeled activation map (MA) was created by modeling coordinate foci $(\mathrm{x}, \mathrm{y}, \mathrm{z})$ with a spherical Gaussian probability distribution, weighted by the number of subjects in each experiment. This is performed to account for spatial uncertainty due to template and between-subject variance (50), and ensure that multiple coordinates from a single experiment does not jointly influence the modeled activation value of a single voxel. Voxel-wise ALE scores were then computed as the union of MA maps, which provide a quantitative assessment of convergence between brain activation across experiments. Then, these maps were cut off by a cluster-forming threshold. In fact, the size of the supra-threshold clusters was compared against a null distribution of cluster sizes derived from artificially created datasets in which foci were shuffled across experiments, but the other properties of original experiments (e.g., number of foci, uncertainty) were kept. Finally, this resulted in calculating the above chance of observing 
a cluster of the given size (51). In the current study, we use the following statistical threshold: a voxel-level cluster forming threshold of $\mathrm{p}<0.001$ and a cluster-level familywise correction ( $\mathrm{pFWE}<0.05)$, with 5,000 permutations $(52)$.

We performed a disorder-specific meta-analysis using these "classical" steps of the ALE method for each diagnostic group, separately.

\subsection{Neurobiologically-driven Meta-analytical procedure}

\subsubsection{Modeled Activation \& Cross-Correlation Matrix (Step 1 \& 2)}

Modeled activation (MA) map was created for each experiment ( $2 \mathrm{~mm}^{3}$ resolution) (Figure 1, Step 1). Each resulting MA map was converted into a 1D feature vector of voxel values (i.e., $2 \mathrm{~mm}^{3}$ grey matter mask in MNI space) and concatenated together to form an experiment (e) by voxel matrix (v) (147 experiments x 226,654 voxels). Pairwise Spearman's rank correlation was performed between the 1D feature vector of each experiments to obtain spatial similarity between maps ( $e$ by $e$ symmetric correlation matrix) (Figure 1, Step 2).

\subsubsection{Correlation-Matrix-Based Hierarchical Clustering (Step 3)}

In order to extract data-driven groups of experiments that showed similar brain topographic map, we performed a Correlation-Matrix-Based Hierarchical Clustering (CMHC) analysis, as previously used on meta-analytic data $(53,54)$. The CMHC was carried out using correlation distance $(1-r)$ (Figure 1. Step 2) and average linkage method. We thus repeated the CMHC for a range of 2 to 15 MAGs. The optimal number of MAGs was determined by comparing frequently used metrics in fMRI clustering (i.e., silhouette and calinski-harabasz indices, variation of information \& adjusted rand index) 
(55), for each of the 2-15 MAGs (See Supplementary Material for more information). More precisely, we used a 90\% subsampling resample strategy (without replacement, 5000 iterations). This implied that we randomly removed $10 \%$ of experiments, iteratively, to perturbate the ability to group the most correlated experiments with each other, successively. Then, for $\mathrm{K}$ range, each metric was compared against a null distribution. To do so, 5,000 datasets were created artificially by shuffling foci locations across experiments but preserving original experiments' properties (e.g., number of foci, sample size). The average of each metric (i.e., silhouette and calinski-harabasz indices) derived from true dataset, was normalized using this null distribution (Average TRUE Average $_{\text {NULL }} /$ STD $_{\text {NULL }}$ ) and then plotted for K range (2-15 MAGs). This improves our ability to select the optimal $\mathrm{K}$ by taking into account the probabilities of getting a certain metric value in a random spatial arrangement. Given that the ground truth class labels are unknown, we compared, for each $\mathrm{K}$, the consistency (adjusted rand index) and shared information distance (variation of information) between Label $_{\text {TRUE }}$ with the Label ${ }_{\text {NULL }}$ then averaged across the 5000 iterations. These metrics were then plotted for K range. A local minimum in the plot suggests a decrease in overlap between both sets of labels.

After finding the optimal number of MAGs, the most stable label solution was found by grouping experiments that were labelled similarly across the 5,000 subsampling iterations. More precisely, we calculated the hamming distance between each experiment's label ids (147 experiments by 5000 iterations ids) to calculate the proportion of disagreement between two experiments' set of labels. A CMHC was performed on a final 147-by-147 experiments' distance matrix, representing the distance 
medRxiv preprint doi: https://doi.org/10.1101/2021.03.18.21253910; this version posted March 20, 2021. The copyright holder for this preprint (which was not certified by peer review) is the author/funder, who has granted medRxiv a license to display the preprint in perpetuity.

It is made available under a CC-BY-NC 4.0 International license .

between each pair of experiments. We then used the determined most optimal number of MAGs to extract the most stable label ids.

Finally. MAGs with less than 10 experiments were considered as outliers and excluded from further analyses, since analyses involving $<10$ experiments drastically increases the risk that a single experiment drives the results (52). All these analyses were performed using Scikit-learn (version 0.21.3) in Python (version 3.7.4) (56).

\subsubsection{Meta-Analytical Groupings (Step 4)}

Experiments $(e)$ within each meta-analytical grouping (MAG) were then metaanalytically processed (Step 4), using the activation likelihood estimate (ALE) algorithm (GingerALE version 3.0.2) $(50,51)$. This was performed to extract significant peaks convergence across each MAG (derived from Step 3). To examine under- and overrepresentations of nosological categories, task and sample characteristics within each MAG, we carried out one-tailed binomial tests comparing their prevalence with their base rate (across all experiments). Main effects of diagnosis, task and sample characteristics between MAGs were investigated through chi-squares $\left(X^{2}\right)$ and Kruskal-Wallis $(\mathrm{H})$ tests. Literature bias was also assessed to compare differences between nosological categories in terms of task and sample characteristics (See Supplementary Material).

Finally, for each MAG, we extracted functional characterization using the Behavioral Analysis plugin of the Multi-Image Analysis GUI (57). A Z-score was calculated using binomial tests for 83 paradigm classes and 51 behavioral subdomains across more than 10,000 experiments. A z-score higher or equal to 3 is considered significant (i.e., equaling $\mathrm{p}<0.05$ Bonferroni corrected for multiple comparisons). 


\section{RESULTS}

\section{$\underline{\text { 3.1. Identified studies and characteristics }}$}

A total of 124 original studies met the inclusion criteria for the meta-analysis, of which 11 involved more than one sample and 8 comprised two or more distinct fMRI task contrasts. This resulted in 147 experiments (1030 foci) involving 3199 cases that were compared to 3024 healthy controls. Also, mean age of cases was 13.8 years old $(\mathrm{SD}=2.25)$ and the average rate of boys across samples was $71.67 \%$. (see Supplementary Table for complete list of studies and their respective characteristics). Interestingly, disorder-specific studies showed significant literature bias regarding the choice of neurocognitive task domains, average of sex ratio, and the average of prescribed medication per samples (See Supplementary Table).

\subsection{Classical ALE Meta-analyses per-disorder category}

Meta-analyses were performed across all foci, independently of the activation direction, for ANX (46 foci, 14 experiments, 293 subjects), DEP (103 foci, 22 experiments, 388 subjects), ADHD (700 foci, 79 experiments, 1892 subjects) and CD (197 foci, 32 experiments, 626 subjects). However, each disorder-specific meta-analysis revealed no significant spatial convergence (See Supplementary Material for results using uncorrected threshold). Nonetheless, we observed peak convergence in dorsal/perigenual ACC $(\mathrm{MNI} x=-8, \mathrm{y}=38, \mathrm{z}=8$, maximum ALE score $=0.0167,129$ voxels $)$ for the internalizing category $(\mathrm{ANX}+\mathrm{DEP})$ and pre-SMA $(\mathrm{x}=4, \mathrm{y}=26, \mathrm{z}=44$, maximum ALE 
medRxiv preprint doi: https://doi.org/10.1101/2021.03.18.21253910; this version posted March 20, 2021. The copyright holder for this preprint (which was not certified by peer review) is the author/funder, who has granted medRxiv a license to display the preprint in perpetuity.

It is made available under a CC-BY-NC 4.0 International license .

score $=0.0279,147$ voxels) for the externalizing category (ADHD+CD/ODD). Additionally, merging experiments across pediatric psychiatric disorders, we observed a significant cluster that included voxels of the right anterior MCC and the presupplementary motor area $(\mathrm{x}=4, \mathrm{y}=24, \mathrm{z}=42$, ALE score $=0.021,323$ voxels $)$. Despite the fact that ADHD (57.14\%) and CD/ODD (35.71\%) largely contributed to this specific brain region, proportions did not significantly differ from their respective base rate. Furthermore, no significant differences were observed regarding nosological categories nor task-characteristics. However, Mann-Whitney U revealed a significant sex effect, indicating that the aMCC/pre-SMA may be associated with higher average rates of boys across samples $(\mathrm{M}=69.7 \%$ versus $\mathrm{M}=91.77 \%$; $\mathrm{U}=479.0 ; \mathrm{p}=0.003)$. No other significant differences were observed.

- $\quad$ Insert Figure 2 About Here -

\subsection{Neurobiologically-driven meta-analysis}

\subsubsection{Clustering Solution}

Clustering solutions were investigated for a range of $K=2-15$ MAGs with resampling method (90\% subsamples and 5,000 iterations). Average of the 5,000 iterations metric values for each $K$ were plotted. Despite that the Calinski-Harabasz index exhibited a monotonic behavior (constantly increasing), the silhouette index showed a stable solution at $\mathrm{K}=8$. Furthermore, aRI plot showed lowest scores at $\mathrm{K}=3$ and $\mathrm{K}=8$, while the greatest increases in variation of information were observed moving from $\mathrm{K}=2$ to $K=3$, from $K=6$ to $K=7$ and $K=7$ to $K=8$. Based on these results, the solution with 8 MAGs was found as the most optimal (See Supplementary Figure 1). 
medRxiv preprint doi: https://doi.org/10.1101/2021.03.18.21253910; this version posted March 20, 2021. The copyright holder for this preprint (which was not certified by peer review) is the author/funder, who has granted medRxiv a license to display the preprint in perpetuity.

It is made available under a CC-BY-NC 4.0 International license .

Of the 8 MAGs, 4 comprised less than 10 experiments $(n=8,3,2 \& 1$, respectively). These were excluded from further analyses. The remaining 4 MAGs represented $90.58 \%$ of total sample of experiments (133 experiments out of 147): MAG1 (577 subjects, 21 experiments and 120 foci), MAG2 (1848 subjects, 87 experiments, 708 foci), MAG3 (197 subjects, 13 experiments, 52 foci), MAG4 (278 subjects, 12 experiments, 113 foci) (Figure 2).

\section{- $\quad$ Insert Figure 3 About Here}

\subsubsection{ALE Meta-analysis}

ALE meta-analysis was performed across experiments in each of the four MAGs, separately, to examine spatial convergence across similar experiments ( $p<0.001$ voxellevel, $\mathrm{p}<0.05$ cluster-level FWE-corrected). As shown in Table 1 and Figure 3, experiments of the MAG-1 had convergent peaks in the right rostrodorsal dorsomedial PFC (dmPFC) and the left caudal dmPFC (see (58)), the left cerebellum (Lobule VI), the right dorsolateral prefrontal cortex (dlPFC, see Cluster 5, Brodmann area (BA) 9/46d, (59)) and the middle temporal gyrus (MTG). The ALE meta-analysis for MAG2 included the right anterior MCC (BA32', see $(60,61))$ and the pre-supplementary motor area, the left amygdala (encompassing the hippocampus and parahippocampus) and the left aMCC (BA24 a'-b', see $(60,61)$ ). Regarding the MAG3, significant aberrant map revealed spatial convergence in the right posterior precentral (BA4p) to postcentral gyri (BA2-3), the right supramarginal gyrus, inferior parietal lobule, human IntraParietal area 2 and the left postcentral gyrus (BA2) and the inferior parietal lobule (PFt area, see (62)). Finally, spatial map of MAG-4 included occipital/cerebellar regions such as bilateral ventral 
medRxiv preprint doi: https://doi.org/10.1101/2021.03.18.21253910; this version posted March 20, 2021. The copyright holder for this preprint (which was not certified by peer review) is the author/funder, who has granted medRxiv a license to display the preprint in perpetuity.

It is made available under a CC-BY-NC 4.0 International license .

extrastriate cortex (right area hOc3v-hOc4v and left hOc4v, (63)), bilateral fusiform gyrus (Area FG4), bilateral Lobule VI, left calcarine gyrus (Area hOc1) as well as right posterior middle/inferior temporal gyrus (hOc1).

- Insert Table 1 About Here -

\subsubsection{Functional characterization of MAGs}

Functional characterization of MAGs (i.e., MAG-wide \& cluster-specific) was performed to examine their relationships with behavioral domains and paradigms of the BrainMap database (see Figure 3, Supplementary Material):

MAG1: Experiments mainly included response inhibition (7) and reward decision-making tasks (5, e.g., monetary incentive delay task, Colorado balloon game). Functional characterization using the BrainMap database yielded no significant behavioral/paradigm classes. However, bilateral dmPFC and anterior MTG/STG were positively associated $(Z>3.0)$ with social cognition/theory of mind, and negative related $(\mathrm{Z}<-3.0)$ with action execution. Interestingly the left Lobule VI show positive association with action execution and negative relationship with social cognition, whereas dIPFC was related to action inhibition. In sum, this MAG may be characterized by deficits of cooccurrent brain regions subserving social cognition during cognitive \& reward decisionmaking tasks.

MAG2: Experiments within this MAG primarily included task contrasts comprising an emotional component $(\mathrm{k}=42)$ of which 24 used negative emotional stimuli (e.g., negative emotional faces). Other main task domains were attentional, cognitive control and reward tasks. MAG2 was characterized by a wide range of behavioral 
medRxiv preprint doi: https://doi.org/10.1101/2021.03.18.21253910; this version posted March 20, 2021. The copyright holder for this preprint (which was not certified by peer review) is the author/funder, who has granted medRxiv a license to display the preprint in perpetuity.

It is made available under a CC-BY-NC 4.0 International license .

subdomains and paradigms from the BrainMap Database including attention, face monitoring \& discrimination and explicit episodic memory. Furthermore, the right aMCC/pre-SMA (Attention) shared similar cognitive domains with left amygdala (Face Monitoring/Discrimination) such as explicit memory, semantic monitoring and positive emotions/reward. Also, the right aMCC/pre-SMA and the left dACC (Somesthesis pain) were both associated with pain monitoring \& discrimination paradigm and somesthesis pain domain. However, the left amygdala and the left dACC did not share any behavioral subdomains or paradigms. Thus, given these findings, the co-occurrence of the dACC, aMCC/pre-SMA and the amygdala may be implicated in stimulus-driven attentional control.

MAG3: Experiments within this MAG included a variety of cognitive and sensorimotor tasks (e.g., finger sequencing, anti-saccade, mental rotation, nback). Using the BrainMap Database, we observed that MAG3 was significantly associated with action execution and finger tapping/button press. Region-specific analyses revealed that the three regions, the right posterior precentral/postcentral (Action Execution), the right SMG (Action Execution) and left postcentral (Action Execution), shared action execution, finger tapping and somesthesis behavioral domains. Additionally, only the right precentral and the left postcentral clusters were both associated with tactile monitoring. In sum, brain regions of this MAG may encompass sensorimotor/action execution processes.

MAG4: Finally, experiments from the MAG4 mainly included various cognitive tasks (10). Functional characterization using the BrainMap database revealed significant associations with vision, passive viewing and speech execution. Region-specific analyses 
medRxiv preprint doi: https://doi.org/10.1101/2021.03.18.21253910; this version posted March 20, 2021. The copyright holder for this preprint (which was not certified by peer review) is the author/funder, who has granted medRxiv a license to display the preprint in perpetuity.

It is made available under a CC-BY-NC 4.0 International license .

revealed that all but the calcarine were related to vision. Furthermore, the right pMTG/ITG, the left pITG/FF and the right lobule VI shared face monitoring/discrimination, passive viewing, vision shape and covert naming domains. In short, MAG4 may reflect co-occurrent deficits in brain regions involved in visual processing during cognitive tasks.

Insert Table 2 About Here -

\subsubsection{Phenotype Assessment 1: Nosological Categories}

MAG1 was less likely to include DEP samples $\left(\mathrm{X}_{2}=4.16, \mathrm{p}=0.041\right)$, compared to all the other MAGs. Indeed, proportions of DEP samples in MAG1 was significantly lower than its base rate $(0 \%$ versus $15.00 \%$, one-tailed $\mathrm{p}=0.028)$ (see Table 2 ). Considering the between-disorder literature bias revealed that the lower rates of DEP samples in MAG1 were replicated when restricting experiments to those using an emotional task contrast and mixed sex samples (Supplementary Material)

Additionally, MAG2 had more DEP samples than other MAGs $\left(\mathrm{X}_{2}=8.43\right.$, $\mathrm{p}=0.004)$. However, compared to its base rate, proportion of DEP samples was not significantly overrepresented in MAG2 (20.7\% versus $15.0 \%$, one-tailed $\mathrm{p}=0.123)$ (see Table 2). After considering the between-disorder literature bias, we observed that the higher rates of DEP samples in MAG2 was replicated when restricting experiments to those using a cognitive task contrast or an emotional task contrast but also in experiments with only medication naïve sample and in mixed sex samples (Supplementary Material)

\subsubsection{Phenotype Assessment 2: Task \& Sample Characteristics}


First, we observed that the rate of experiments within the MAG1 that included a positive emotional stimulus was higher than other MAGs $\left(\mathrm{X}_{2}=8.62, \mathrm{p}=0.003\right)$, and significantly overrepresented compared to its base rate $(28.6 \%$ versus $11.6 \%$, one-tailed $\mathrm{p}=0.028)($ see Table 2).

Additionally, experiments in MAG2 were less likely to include positive emotional task contrast $\left(\mathrm{X}_{2}=3.97, \mathrm{p}=0.046\right)$ and marginally associated with greater experiments with negative emotion task contrast $\left(\mathrm{X}_{2}=3.31, \mathrm{p}=0.069\right)$ (see Table 2$)$, compared to other MAGs. However, proportions of these task domains were not statistically different than their base rates.

MAG3 had significantly lower rate of general emotional stimuli compared to other MAGs $\left(\mathrm{X}_{2}=4.20, \mathrm{p}=0.040\right)$, which was marginally lower compared to its base rate ( $37.5 \%$ versus $48.3 \%$, one-tailed $\mathrm{p}=0.059)$. Other characteristics did not reach statistical significance, compared to their base rates.

Also, despite that the MAG1 had significantly higher rate of medication-naïve subjects, compared to its base rate (one-tailed $\mathrm{p}=0.018$ ), MAGs did not differ in rates of experiments with medication-naïve samples $\left(\mathrm{X}^{2}=2.25, \mathrm{p}=0.522\right)$, in the average rate of prescribed medication (Kruskal-Wall $\mathrm{H}=2.74, \mathrm{p}=0.433$ ). No differences were observed concerning the rate of mixed sex samples $\left(\mathrm{X}^{2}=1.90, \mathrm{p}=0.594\right)$ and in the average rate of boys in samples (Kruskal-Wall $\mathrm{H}=2.40, \mathrm{p}=0.493$ ).

\section{Discussion}

The current meta-analysis was carried out to examine the shared and/or specific neural correlates of pediatric psychiatric disorders (ADHD, CD/ODD, ANX \& DEP). To 
do so, we used a novel data-driven meta-analytical method that aimed to extract groups of experiments which show similar brain topographic maps. We identified 4 significant MAGs, which comprised co-occurrent deficits in brain regions that may share features with (1) internally/externally directed processes; (2) attentional control of emotions, (3) action execution and (4) visual processes. More importantly, we found underrepresentation of DEP samples in MAG1 but overrepresentation of samples in MAG2. No other significant differences in nosological categories between MAGs we found.

MAG1 included bilateral dmPFC, dlPFC, MTG/STG and Lobule VI. More precisely, we observed that dmPFC-MTG/STG were involved in social cognitions, whereas dlPFC and Lobule VI were characterized as action inhibition and execution, respectively. We also found main task-effect of the utilization of a positive emotional stimulus. Interestingly, several findings suggest that during some cognitively demanding tasks, brain regions involved in internally directed processes (e.g., dmPFC \& anterior MTG/STG) flexibly shifts their activity to enable goal-directed processes (e.g., dlPFC \& Lobule VI) (64-66). Given these data, deficits in brain regions involved in MAG1 may reflect a failure to disengage internal processes at the cost of goal-directed processes (67).

Interestingly, our results suggest that these co-occurrent deficits (i.e., dmPFC, dlPFC, Lobule VI and MTG/STG) are less likely to be reported in that DEP samples given that none of the DEP samples was grouped in MAG1. However, a recent study has shown lower thickness in regions spanning the MAG1 (i.e., encompassing the frontoparietal and default-mode network) associated externalizing but also internalizing factors (68). Furthermore, meta-analytical evidence suggests dysconnectivity between the 
default-mode and dorsolateral prefrontal cortex (fronto-parietal network) in DEP (69). Given that these findings were observed in adult samples and that anticorrelation between these processes varies from childhood from adulthood (70), it is possible that these deficits may rather be observed in adulthood DEP. Additionally, DEP samples did not frequently use positive emotional stimuli ( $k=3$ out of 22 ), which was found to be main task-characteristic of MAG1. As such, this may suggest that the lack of relationship between MAG and DEP may be explained by task differences. Considering the small sample size involved, we cannot completely rule out the possibility of such deficits in children with DEP.

The largest MAG (MAG2, k=87) was constituted of the aMCC/pre-SMA, amygdala and dACC. This MAG was mainly characterized by attention, face monitoring and explicit episodic memory, using the BrainMap database. Interestingly, deficits in these brain regions were associated with higher rates of DEP samples, in comparison with other MAGs. This is somewhat expected given the large number of meta-analytical evidence consistently showing aberrant activation in these particular regions during negative emotional tasks in adult with major depression (42-47). However, no effect was observed in ANX samples, potentially due to the limited sample size. Nonetheless, deficits in these regions were also observed across adult ANX \& DEP samples, during negative emotion processing $(20,22,71)$. In addition, we observed a marginally significant association between this MAG and negative emotional stimuli, indicating a possible task-effect. In fact, although rates of ADHD ( $\approx 50 \%)$, CD/ODD $(\approx 20 \%)$ did not differ between other MAGs, evidence suggests that these disorders may also show deficits in MAG2 regions, particularly during emotion processing tasks $(31,72)$ which 
medRxiv preprint doi: https://doi.org/10.1101/2021.03.18.21253910; this version posted March 20, 2021. The copyright holder for this preprint (which was not certified by peer review) is the author/funder, who has granted medRxiv a license to display the preprint in perpetuity.

It is made available under a CC-BY-NC 4.0 International license .

correlates with general psychopathology score $(68,73,74)$. In sum, this MAG may reflect general deficits in emotional lability, inherent to DEP, yet frequently observed in children/adolescent with ADHD (75) and/or CD (76).

We also found deficits in brain regions (e.g., pre- and postcentral gyrus) subserving action execution/finger tapping tasks (MAG3). This MAG was less likely to comprise emotional tasks, which is consistent with the fact that emotional tasks usually require less motor execution. Interestingly, deficits in similar regions (i.e., somato-motor network) were also observed in a recent study showing significant transdiagnostic association with general maladaptive functionality (77). Although deficits in these regions are currently not well understood, sensory deficits such as tactile perception and body awareness are often reported in children with pediatric psychiatric disorders (7882). It is thus possible that abnormalities in MAG3 may reflect deficits in tactile perception, crucial for accurate performance of purposeful movements (83) such as in cognitive tasks.

Finally, we found evidence of early processing deficits across disorders (MAG4). However, this MAG was not specifically associated with sample- or task-characteristics. Recent studies have shown replicable structural alterations in brain regions spanning this MAG. In fact, the authors demonstrated, through two different samples comprising 1246 (84) and 875 (85) subjects, that the general psychopathology factor score was associated with deficits in occipital (i.e., Lingual, Calcarine cortex) and cerebellum regions. These regions are implicated in variety of visual functions such as detecting relevant changes in the environment (e.g., visual oddball) $(86,87)$. Thus, MAG4 may mirror several dysfunctional processes in early visual processing, including gazing at task-irrelevant 
medRxiv preprint doi: https://doi.org/10.1101/2021.03.18.21253910; this version posted March 20, 2021. The copyright holder for this preprint

stimuli. For example, during face-emotion tasks, the number and duration of fixation to the eye regions have been reported to be significantly lower in ADHD with and without CD (88), in childhood psychopathic traits (89), in ODD/CD (90-92), anxiety disorders (93-95) (96)) and depression (97, 98). Likewise, deficits in the ability to filter out irrelevant stimuli are also observed in continuous performance test (99) and visual search tasks (98) in these populations.

In the classical transdiagnostic approach, we observed significant overlaps in the aMCC/pre-SMA. Furthermore, we found that externalizing disorders (i.e., ADHD, $\mathrm{CD} / \mathrm{ODD}$ ) were associated with deficits in the pre-SMA, whereas internalizing disorders (i.e., ANX, DEP) yielded aberrant activity in the dorsal/perigenual ACC. These concur with recent transdiagnostic findings in adult samples showing aberrant activation during cognitive control tasks (dACC \& aMCC (21)). It is worth mentioning that in children diagnosed with a psychiatric disorder, more than half will receive, at least, an additional diagnosis than their primary one in the following years (100-105). Also, comorbidity rates are higher within externalizing (between CD/ODD \& ADHD) and internalizing (between DEP and ANX) disorders than between these broad categories. However, it remains unknown whether this high comorbidity rate in children is due to a common vulnerability (e.g., shared risk factors) or the presence of cross-cutting criteria (e.g., impulsivity, neuroticism). Hence, this issue unequivocally needs to be tackled in the future. In addition, we observed no significant peak convergence across each of the disorder-specific meta-analysis. Indeed, this lack of convergence concurs with results from recent meta-analyses which revealed similar results in CD/ODD, ADHD and DEP, using a somewhat conservative threshold $(\mathrm{p}<0.001, \mathrm{cFWE}<0.05)(28,31,106)$. These 
null findings were also observed even when examining specific neurocognitive task domains. Despite that this lack of convergence might have been attributable to a number of between-study differences (e.g., stimulus, sex effect, statistical threshold, sample size), one possibility that deserves careful attention is the within-disorder heterogeneity. Indeed, it is generally well accepted that DSM-derived categories comprise subfactors that are characterized by different psychological processes (107-112). Thus, this plurality in criteria substantially increases the risk of finding distinct set of symptoms while still meeting the diagnostic threshold (from 42 [GAD] to 116,200 [ADHD] theoretical set of criteria, $(113,114)$. Therefore, we could not rule out the possibility that increasing the sample size in meta-analyses, which also increase the between-sample heterogeneity, may reduce the ability to detect robust findings. In sum, irrespectively of the nosological categories or task-characteristics, we found 4 significant groups of aberrant brain regions in children/adolescent with a psychiatric disorder, which comprised relatively similar rates of $\mathrm{ADHD}, \mathrm{ANX}, \mathrm{CD} / \mathrm{ODD}$ (and DEP to a lesser extent).

\section{LIMITATIONS}

First, we performed cluster analysis across pediatric psychiatric disorders and across fMRI paradigms. Since there were limited data available to perform domainspecific analyses, it is possible that our results may have been altered by literature bias (see Supplementary Material) concerning the use of particular neurocognitive task domains per diagnosis category. However, subanalyses were carried out to examine these confound effects. In the following years, as more samples using different tasks domains will be available, more precise analyses will be possible. Second, the limited sample size 
for the ANX samples $(\mathrm{k}=14)$ may have explained the null findings in classical disorderspecific meta-analysis as well as the lack of over/underrepresentation across MAGs. It has been recommended that a sample size greater than 17 experiments are required to achieve good statistical power in classical meta-analyses. Finally, we used hierarchical clustering with spearman correlation as distance measure and average linkage algorithm. Although these parameters are frequently utilized in studies using similar meta-analytical approaches, it is possible that the most optimal set of parameters would have been specific to our study.

\section{CONCLUSIONS}

In sum, we observed transdiagnostic neural signatures across common pediatric psychiatric disorders. More particularly, the identified groups of co-occurrent deficits spanned brain regions that share features with internally/externally directed processes, emotional lability, somato-motor \& visual processes. We also observed that DEP samples were less likely to display aberrant co-activation map involving internally/externally directed processes, but more likely to exhibit deficits in brain regions implicated in attentional control of emotions. Also, these MAGs did not specifically fit particular neurocognitive domains. Indeed, they rather involved multiple subprocesses (e.g., Selfreflective \& Execution/Inhibition; Threat system \& Attentional Control). Thus, future studies may benefit from examining the task-based functional connectivity between subprocesses and their relationship between psychopathologies. Our study also underscores the need for studying pediatric psychiatric disorders simultaneously rather 
than independently, as well as studying the within-disorder heterogeneity and the high rates of comorbidity among children with psychiatric disorders.

\section{Acknowledgments}

JRD is holder of a doctoral scholarship from the Fonds de Recherche du Québec en Santé (FRQS). SP is holder of the Eli Lilly Canada Chair on schizophrenia research.

We also would like to thank Dr. Angela Laird and the Neuroinformatics and Brain Connectivity Lab who have made publicly available the code that was used and modified for the specific purposes of the current study.

\section{Disclosures}

SBE was supported by the Deutsche Forschungsgemeinschaft (DFG), the National Institute of Mental Health (R01-MH074457), the Helmholtz Portfolio Theme "Supercomputing and Modeling for the Human Brain", ad the European Union's Horizon 2020 Research and Innovation Programme under Grant Agreement No. 945539 (HBP SGA3) 


\section{REFERENCES}

1. Polanczyk GV, Salum GA, Sugaya LS, Caye A, Rohde LA (2015): Annual research review: A meta-analysis of the worldwide prevalence of mental disorders in children and adolescents. Journal of child psychology and psychiatry. 56:345-365.

2. Angold A, Costello EJ, Erkanli A (1999): Comorbidity. The Journal of Child Psychology and Psychiatry and Allied Disciplines. 40:57-87.

3. Bird HR, Davies M, Duarte CS, Shen S, Loeber R, Canino GJ (2006): A study of disruptive behavior disorders in Puerto Rican youth: II. Baseline prevalence, comorbidity, and correlates in two sites. Journal of the American Academy of Child \& Adolescent Psychiatry. 45:1042-1053.

4. Costello EJ, Mustillo S, Erkanli A, Keeler G, Angold A (2003): Prevalence and development of psychiatric disorders in childhood and adolescence. Archives of general psychiatry. 60:837-844.

5. Park KJ, Lee JS, Kim H-W (2017): Medical and psychiatric comorbidities in korean children and adolescents with attention-deficit/hyperactivity disorder. Psychiatry Investigation. 14:817.

6. Wichstrøm L, Berg-Nielsen TS, Angold A, Egger HL, Solheim E, Sveen TH (2012): Prevalence of psychiatric disorders in preschoolers. Journal of Child Psychology and Psychiatry. 53:695-705.

7. Boylan K, Vaillancourt T, Boyle M, Szatmari P (2007): Comorbidity of internalizing disorders in children with oppositional defiant disorder. European child \& adolescent psychiatry. 16:484-494.

8. Nock MK, Kazdin AE, Hiripi E, Kessler RC (2006): Prevalence, subtypes, and correlates of DSMIV conduct disorder in the National Comorbidity Survey Replication. Psychological medicine. 36:699.

9. Weller BE, Blanford KL, Butler AM (2018): Estimated Prevalence of Psychiatric Comorbidities in US Adolescents With Depression by Race/Ethnicity, 2011-2012. Journal of Adolescent Health. 62:716721.

10. Rhee SH, Lahey BB, Waldman ID (2015): Comorbidity among dimensions of childhood psychopathology: Converging evidence from behavior genetics. Child development perspectives. 9:26-31.

11. Sullivan PF, Daly MJ, O'donovan M (2012): Genetic architectures of psychiatric disorders: the emerging picture and its implications. Nature Reviews Genetics. 13:537-551.

12. Walters RK, Polimanti R, Johnson EC, McClintick JN, Adams MJ, Adkins AE, et al. (2018): Transancestral GWAS of alcohol dependence reveals common genetic underpinnings with psychiatric disorders. Nature neuroscience. 21:1656-1669.

13. Consortium C-DGotPG (2013): Identification of risk loci with shared effects on five major psychiatric disorders: a genome-wide analysis. The Lancet. 381:1371-1379.

14. Network T, O'Dushlaine C, Rossin L, Lee PH, Duncan L, Parikshak NN, et al. (2015): Psychiatric genome-wide association study analyses implicate neuronal, immune and histone pathways. Nature neuroscience. 18:199.

15. Cerdá M, Sagdeo A, Johnson J, Galea S (2010): Genetic and environmental influences on psychiatric comorbidity: a systematic review. Journal of affective disorders. 126:14-38.

16. Keyes KM, Eaton NR, Krueger RF, McLaughlin KA, Wall MM, Grant BF, et al. (2012): Childhood maltreatment and the structure of common psychiatric disorders. The British Journal of Psychiatry. 200:107-115.

17. Tackett JL, Lahey BB, Van Hulle C, Waldman I, Krueger RF, Rathouz PJ (2013): Common genetic influences on negative emotionality and a general psychopathology factor in childhood and adolescence. Journal of abnormal psychology. 122:1142.

18. Gong Q, Scarpazza C, Dai J, He M, Xu X, Shi Y, et al. (2019): A transdiagnostic neuroanatomical signature of psychiatric illness. Neuropsychopharmacology. 44:869-875.

19. Goodkind M, Eickhoff SB, Oathes DJ, Jiang Y, Chang A, Jones-Hagata LB, et al. (2015): Identification of a common neurobiological substrate for mental illness. JAMA psychiatry. 72:305-315.

20. Janiri D, Moser DA, Doucet GE, Luber MJ, Rasgon A, Lee WH, et al. (2020): Shared neural phenotypes for mood and anxiety disorders: a meta-analysis of 226 task-related functional imaging studies. JAMA psychiatry. 77:172-179.

21. McTeague LM, Huemer J, Carreon DM, Jiang Y, Eickhoff SB, Etkin A (2017): Identification of common neural circuit disruptions in cognitive control across psychiatric disorders. American Journal of Psychiatry. 174:676-685. 
22. McTeague LM, Rosenberg BM, Lopez JW, Carreon DM, Huemer J, Jiang Y, et al. (2020): Identification of common neural circuit disruptions in emotional processing across psychiatric disorders. American Journal of Psychiatry. 177:411-421.

23. Cortese S, Kelly C, Chabernaud C, Proal E, Di Martino A, Milham MP, et al. (2012): Toward systems neuroscience of ADHD: a meta-analysis of 55 fMRI studies. American Journal of Psychiatry. 169:1038-1055.

24. Dickstein SG, Bannon K, Xavier Castellanos F, Milham MP (2006): The neural correlates of attention deficit hyperactivity disorder: An ALE meta-analysis. Journal of Child Psychology and Psychiatry. 47:1051-1062.

25. Hart H, Radua J, Mataix-Cols D, Rubia K (2012): Meta-analysis of fMRI studies of timing in attention-deficit hyperactivity disorder (ADHD). Neuroscience \& Biobehavioral Reviews. 36:2248-2256.

26. Hart H, Radua J, Nakao T, Mataix-Cols D, Rubia K (2013): Meta-analysis of functional magnetic resonance imaging studies of inhibition and attention in attention-deficit/hyperactivity disorder: exploring task-specific, stimulant medication, and age effects. JAMA psychiatry. 70:185-198.

27. Lei D, Du M, Wu M, Chen T, Huang X, Du X, et al. (2015): Functional MRI reveals different response inhibition between adults and children with ADHD. Neuropsychology. 29:874.

28. Samea F, Soluki S, Nejati V, Zarei M, Cortese S, Eickhoff SB, et al. (2019): Brain alterations in children/adolescents with ADHD revisited: A neuroimaging meta-analysis of 96 structural and functional studies. Neuroscience \& Biobehavioral Reviews. 100:1-8.

29. Alegria AA, Radua J, Rubia K (2016): Meta-analysis of fMRI studies of disruptive behavior disorders. American Journal of Psychiatry. 173:1119-1130.

30. Deming P, Koenigs M (2020): Functional neural correlates of psychopathy: a meta-analysis of MRI data. Translational psychiatry. 10:1-8.

31. Dugré JR, Radua J, Carignan-Allard M, Dumais A, Rubia K, Potvin S (2020): Neurofunctional abnormalities in antisocial spectrum: A meta-analysis of fMRI studies on Five distinct neurocognitive research domains. Neuroscience \& Biobehavioral Reviews.

32. Noordermeer SD, Luman M, Oosterlaan J (2016): A systematic review and meta-analysis of neuroimaging in oppositional defiant disorder (ODD) and conduct disorder (CD) taking attention-deficit hyperactivity disorder (ADHD) into account. Neuropsychology review. 26:44-72.

33. Poeppl TB, Donges MR, Mokros A, Rupprecht R, Fox PT, Laird AR, et al. (2019): A view behind the mask of sanity: meta-analysis of aberrant brain activity in psychopaths. Molecular psychiatry. 24:463.

34. Blackford JU, Pine DS (2012): Neural substrates of childhood anxiety disorders: a review of neuroimaging findings. Child and Adolescent Psychiatric Clinics. 21:501-525.

35. Etkin A, Wager TD (2007): Functional neuroimaging of anxiety: a meta-analysis of emotional processing in PTSD, social anxiety disorder, and specific phobia. American journal of Psychiatry. 164:1476-1488.

36. Kolesar TA, Bilevicius E, Wilson AD, Kornelsen J (2019): Systematic review and meta-analyses of neural structural and functional differences in generalized anxiety disorder and healthy controls using magnetic resonance imaging. NeuroImage: Clinical. 24:102016.

37. Madonna D, Delvecchio G, Soares JC, Brambilla P (2019): Structural and functional neuroimaging studies in generalized anxiety disorder: a systematic review. Brazilian Journal of Psychiatry. 41:336-362.

38. Pine DS, Guyer AE, Leibenluft E (2008): Functional magnetic resonance imaging and pediatric anxiety. Journal of the American Academy of Child and Adolescent Psychiatry. 47:1217.

39. Milani ACC, Hoffmann EV, Fossaluza V, Jackowski AP, Mello MF (2017): Does pediatric post-traumatic stress disorder alter the brain? Systematic review and meta-analysis of structural and functional magnetic resonance imaging studies. Psychiatry and Clinical Neurosciences. 71:154-169.

40. Miller CH, Hamilton JP, Sacchet MD, Gotlib IH (2015): Meta-analysis of functional neuroimaging of major depressive disorder in youth. JAMA psychiatry. 72:1045-1053.

41. Hulvershorn LA, Cullen K, Anand A (2011): Toward dysfunctional connectivity: a review of neuroimaging findings in pediatric major depressive disorder. Brain imaging and behavior. 5:307-328.

42. Graham J, Salimi-Khorshidi G, Hagan C, Walsh N, Goodyer I, Lennox B, et al. (2013): Metaanalytic evidence for neuroimaging models of depression: state or trait? Journal of affective disorders. 151:423-431.

43. Fitzgerald PB, Laird AR, Maller J, Daskalakis ZJ (2008): A meta-analytic study of changes in brain activation in depression. Human brain mapping. 29:683-695. 
44. Hamilton JP, Etkin A, Furman DJ, Lemus MG, Johnson RF, Gotlib IH (2012): Functional neuroimaging of major depressive disorder: a meta-analysis and new integration of baseline activation and neural response data. American Journal of Psychiatry. 169:693-703.

45. Delvecchio G, Fossati P, Boyer P, Brambilla P, Falkai P, Gruber O, et al. (2012): Common and distinct neural correlates of emotional processing in bipolar disorder and major depressive disorder: a voxel-based meta-analysis of functional magnetic resonance imaging studies. European Neuropsychopharmacology. 22:100-113.

46. Palmer SM, Crewther SG, Carey LM (2015): A meta-analysis of changes in brain activity in clinical depression. Frontiers in human neuroscience. 8:1045.

47. Lai C-H (2014): Patterns of cortico-limbic activations during visual processing of sad faces in depression patients: a coordinate-based meta-analysis. The Journal of neuropsychiatry and clinical neurosciences. 26:34-43.

48. Sprooten E, Rasgon A, Goodman M, Carlin A, Leibu E, Lee WH, et al. (2017): Addressing reverse inference in psychiatric neuroimaging: Meta-analyses of task-related brain activation in common mental disorders. Human brain mapping. 38:1846-1864.

49. Schmaal L, van Harmelen A-L, Chatzi V, Lippard ET, Toenders YJ, Averill LA, et al. (2020): Imaging suicidal thoughts and behaviors: a comprehensive review of 2 decades of neuroimaging studies. Molecular psychiatry. 25:408-427.

50. Eickhoff SB, Laird AR, Grefkes C, Wang LE, Zilles K, Fox PT (2009): Coordinate-based activation likelihood estimation meta-analysis of neuroimaging data: A random-effects approach based on empirical estimates of spatial uncertainty. Human brain mapping. 30:2907-2926.

51. Eickhoff SB, Bzdok D, Laird AR, Kurth F, Fox PT (2012): Activation likelihood estimation metaanalysis revisited. Neuroimage. 59:2349-2361.

52. Eickhoff SB, Nichols TE, Laird AR, Hoffstaedter F, Amunts K, Fox PT, et al. (2016): Behavior, sensitivity, and power of activation likelihood estimation characterized by massive empirical simulation. Neuroimage. 137:70-85.

53. Laird AR, Riedel MC, Sutherland MT, Eickhoff SB, Ray KL, Uecker AM, et al. (2015): Neural architecture underlying classification of face perception paradigms. Neuroimage. 119:70-80.

54. Riedel MC, Yanes JA, Ray KL, Eickhoff SB, Fox PT, Sutherland MT, et al. (2018): Dissociable meta-analytic brain networks contribute to coordinated emotional processing. Human brain mapping. 39:2514-2531.

55. Eickhoff SB, Thirion B, Varoquaux G, Bzdok D (2015): Connectivity-based parcellation: Critique and implications. Human brain mapping. 36:4771-4792.

56. Pedregosa F, Varoquaux G, Gramfort A, Michel V, Thirion B, Grisel O, et al. (2011): Scikit-learn: Machine learning in Python. the Journal of machine Learning research. 12:2825-2830.

57. Lancaster JL, Laird AR, Eickhoff SB, Martinez MJ, Fox PM, Fox PT (2012): Automated regional behavioral analysis for human brain images. Frontiers in neuroinformatics. 6:23.

58. Eickhoff SB, Laird AR, Fox PT, Bzdok D, Hensel L (2016): Functional segregation of the human dorsomedial prefrontal cortex. Cerebral cortex. 26:304-321.

59. Sallet J, Mars RB, Noonan MP, Neubert F-X, Jbabdi S, O'Reilly JX, et al. (2013): The organization of dorsal frontal cortex in humans and macaques. Journal of Neuroscience. 33:12255-12274.

60. Palomero-Gallagher N, Vogt BA, Schleicher A, Mayberg HS, Zilles K (2009): Receptor architecture of human cingulate cortex: evaluation of the four-region neurobiological model. Human brain mapping. 30:2336-2355.

61. VOGT BA, VOGT LJ, HOF PR (2004): Cingulate gyrus. The human nervous system: Elsevier, pp 915-949.

62. Caspers S, Geyer S, Schleicher A, Mohlberg H, Amunts K, Zilles K (2006): The human inferior parietal cortex: cytoarchitectonic parcellation and interindividual variability. Neuroimage. 33:430-448.

63. Rottschy C, Eickhoff SB, Schleicher A, Mohlberg H, Kujovic M, Zilles K, et al. (2007): Ventral visual cortex in humans: cytoarchitectonic mapping of two extrastriate areas. Human brain mapping. 28:1045-1059.

64. Fox MD, Snyder AZ, Vincent JL, Corbetta M, Van Essen DC, Raichle ME (2005): The human brain is intrinsically organized into dynamic, anticorrelated functional networks. Proceedings of the National Academy of Sciences. 102:9673-9678.

65. Kim H, Daselaar SM, Cabeza R (2010): Overlapping brain activity between episodic memory encoding and retrieval: roles of the task-positive and task-negative networks. Neuroimage. 49:1045-1054. 
66. Shulman GL, Corbetta M, Buckner RL, Fiez JA, Miezin FM, Raichle ME, et al. (1997): Common blood flow changes across visual tasks: I. Increases in subcortical structures and cerebellum but not in nonvisual cortex. Journal of cognitive neuroscience. 9:624-647.

67. Anticevic A, Cole MW, Murray JD, Corlett PR, Wang X-J, Krystal JH (2012): The role of default network deactivation in cognition and disease. Trends in cognitive sciences. 16:584-592.

68. Romer AL, Elliott ML, Knodt AR, Sison ML, Ireland D, Houts R, et al. (2020): Pervasively thinner neocortex as a transdiagnostic feature of general psychopathology. American Journal of Psychiatry.appi. ajp. 2020.19090934.

69. Kaiser RH, Andrews-Hanna JR, Wager TD, Pizzagalli DA (2015): Large-scale network dysfunction in major depressive disorder: a meta-analysis of resting-state functional connectivity. JAMA psychiatry. 72:603-611.

70. DeSerisy M, Ramphal B, Pagliaccio D, Raffanello E, Tau G, Marsh R, et al. (2021): Frontoparietal and default mode network connectivity varies with age and intelligence. Developmental cognitive neuroscience. 48:100928.

71. Zilverstand A, Parvaz MA, Goldstein RZ (2017): Neuroimaging cognitive reappraisal in clinical populations to define neural targets for enhancing emotion regulation. A systematic review. Neuroimage. 151:105-116.

72. Rubia K (2018): Cognitive neuroscience of attention deficit hyperactivity disorder (ADHD) and its clinical translation. Frontiers in human neuroscience. 12:100.

73. Kaczkurkin AN, Moore TM, Calkins ME, Ciric R, Detre JA, Elliott MA, et al. (2018): Common and dissociable regional cerebral blood flow differences associate with dimensions of psychopathology across categorical diagnoses. Molecular psychiatry. 23:1981-1989.

74. Shanmugan S, Wolf DH, Calkins ME, Moore TM, Ruparel K, Hopson RD, et al. (2016): Common and dissociable mechanisms of executive system dysfunction across psychiatric disorders in youth. American journal of psychiatry. 173:517-526.

75. Sobanski E, Banaschewski T, Asherson P, Buitelaar J, Chen W, Franke B, et al. (2010): Emotional lability in children and adolescents with attention deficit/hyperactivity disorder (ADHD): clinical correlates and familial prevalence. Journal of Child Psychology and Psychiatry. 51:915-923.

76. Kohls G, Baumann S, Gundlach M, Scharke W, Bernhard A, Martinelli A, et al. (2020): Investigating sex differences in emotion recognition, learning, and regulation among youths with conduct disorder. Journal of the American Academy of Child \& Adolescent Psychiatry. 59:263-273.

77. Van Dam NT, O’Connor D, Marcelle ET, Ho EJ, Craddock RC, Tobe RH, et al. (2017): Datadriven phenotypic categorization for neurobiological analyses: beyond DSM-5 labels. Biological psychiatry. 81:484-494.

78. Fox C, Snow PC, Holland K (2014): The relationship between sensory processing difficulties and behaviour in children aged 5-9 who are at risk of developing conduct disorder. Emotional and behavioural difficulties. 19:71-88.

79. He JL, Wodka E, Tommerdahl M, Edden RA, Mikkelsen M, Mostofsky SH, et al. (2021): Disorder-specific alterations of tactile sensitivity in neurodevelopmental disorders. Communications biology. 4:1-15.

80. Puts NA, Harris AD, Mikkelsen M, Tommerdahl M, Edden RA, Mostofsky SH (2017): Altered tactile sensitivity in children with attention-deficit hyperactivity disorder. Journal of neurophysiology. 118:2568-2578.

81. Ghanizadeh A (2011): Sensory processing problems in children with ADHD, a systematic review. Psychiatry investigation. 8:89.

82. Gourley L, Wind C, Henninger EM, Chinitz S (2013): Sensory processing difficulties, behavioral problems, and parental stress in a clinical population of young children. Journal of child and family studies. 22:912-921.

83. Borich M, Brodie S, Gray W, Ionta S, Boyd L (2015): Understanding the role of the primary somatosensory cortex: Opportunities for rehabilitation. Neuropsychologia. 79:246-255.

84. Romer AL, Knodt AR, Houts R, Brigidi BD, Moffitt TE, Caspi A, et al. (2018): Structural alterations within cerebellar circuitry are associated with general liability for common mental disorders. Molecular psychiatry. 23:1084-1090.

85. Romer AL, Knodt AR, Sison ML, Ireland D, Houts R, Ramrakha S, et al. (2019): Replicability of structural brain alterations associated with general psychopathology: evidence from a populationrepresentative birth cohort. Molecular Psychiatry.1-8. 
86. Downar J, Crawley AP, Mikulis DJ, Davis KD (2000): A multimodal cortical network for the detection of changes in the sensory environment. Nature neuroscience. 3:277-283.

87. Kim H (2014): Involvement of the dorsal and ventral attention networks in oddball stimulus processing: A meta-analysis. Human brain mapping. 35:2265-2284.

88. Airdrie JN, Langley K, Thapar A, van Goozen SH (2018): Facial emotion recognition and eye gaze in attention-deficit/hyperactivity disorder with and without comorbid conduct disorder. Journal of the American Academy of Child \& Adolescent Psychiatry. 57:561-570.

89. Dadds MR, El Masry Y, Wimalaweera S, Guastella AJ (2008): Reduced eye gaze explains "fear blindness" in childhood psychopathic traits. Journal of the American Academy of Child \& Adolescent Psychiatry. 47:455-463.

90. Bours C, Bakker-Huvenaars M, Tramper J, Bielczyk N, Scheepers F, Nijhof K, et al. (2018): Emotional face recognition in male adolescents with autism spectrum disorder or disruptive behavior disorder: an eye-tracking study. European child \& adolescent psychiatry. 27:1143-1157.

91. Menks WM, Fehlbaum LV, Borbás R, Sterzer P, Stadler C, Raschle NM (2020): Eye gaze patterns and functional brain responses during emotional face processing in adolescents with conduct disorder. NeuroImage: Clinical. 29:102519.

92. Martin-Key NA, Graf E, Adams W, Fairchild G (2018): Facial emotion recognition and eye movement behaviour in conduct disorder. Journal of Child Psychology and Psychiatry. 59:247-257.

93. Horley K, Williams LM, Gonsalvez C, Gordon E (2003): Social phobics do not see eye to eye:: A visual scanpath study of emotional expression processing. Journal of anxiety disorders. 17:33-44.

94. Horley K, Williams LM, Gonsalvez C, Gordon E (2004): Face to face: visual scanpath evidence for abnormal processing of facial expressions in social phobia. Psychiatry research. 127:43-53.

95. Weeks JW, Howell AN, Goldin PR (2013): Gaze avoidance in social anxiety disorder. Depression and anxiety. 30:749-756.

96. Michalska KJ, Machlin L, Moroney E, Lowet DS, Hettema JM, Roberson-Nay R, et al. (2017): Anxiety symptoms and children's eye gaze during fear learning. Journal of Child Psychology and Psychiatry. 58:1276-1286.

97. Noiret N, Carvalho N, Laurent É, Vulliez L, Bennabi D, Chopard G, et al. (2015): Visual scanning behavior during processing of emotional faces in older adults with major depression. Aging \& Mental Health. 19:264-273.

98. Armstrong T, Olatunji BO (2012): Eye tracking of attention in the affective disorders: A metaanalytic review and synthesis. Clinical psychology review. 32:704-723.

99. Lev A, Braw Y, Elbaum T, Wagner M, Rassovsky Y (2020): Eye Tracking During a Continuous Performance Test: Utility for Assessing ADHD Patients. Journal of Attention Disorders.1087054720972786.

100. Egger HL, Angold A (2006): Common emotional and behavioral disorders in preschool children: presentation, nosology, and epidemiology. Journal of child psychology and psychiatry. 47:313-337.

101. Fleitlich-Bilyk B, Goodman R (2004): Prevalence of child and adolescent psychiatric disorders in southeast Brazil. Journal of the American Academy of Child \& Adolescent Psychiatry. 43:727-734.

102. Ford T, Goodman R, Meltzer H (2003): The British child and adolescent mental health survey 1999: the prevalence of DSM-IV disorders. Journal of the American academy of child \& adolescent psychiatry. 42:1203-1211.

103. Kessler RC, Wang PS (2008): The descriptive epidemiology of commonly occurring mental disorders in the United States. Annu Rev Public Health. 29:115-129.

104. Merikangas KR, He J-p, Burstein M, Swanson SA, Avenevoli S, Cui L, et al. (2010): Lifetime prevalence of mental disorders in US adolescents: results from the National Comorbidity Survey Replication-Adolescent Supplement (NCS-A). Journal of the American Academy of Child \& Adolescent Psychiatry. 49:980-989.

105. Petresco S, Anselmi L, Santos IS, Barros AJ, Fleitlich-Bilyk B, Barros FC, et al. (2014): Prevalence and comorbidity of psychiatric disorders among 6-year-old children: 2004 Pelotas Birth Cohort. Social psychiatry and psychiatric epidemiology. 49:975-983.

106. Müller VI, Cieslik EC, Serbanescu I, Laird AR, Fox PT, Eickhoff SB (2017): Altered brain activity in unipolar depression revisited: meta-analyses of neuroimaging studies. JAMA psychiatry. 74:4755 . 
medRxiv preprint doi: https://doi.org/10.1101/2021.03.18.21253910; this version posted March 20, 2021. The copyright holder for this preprint (which was not certified by peer review) is the author/funder, who has granted medRxiv a license to display the preprint in perpetuity.

It is made available under a CC-BY-NC 4.0 International license .

107. Burns GL, Boe B, Walsh JA, Sommers-Flanagan R, Teegarden LA (2001): A confirmatory factor analysis on the DSM-IV ADHD and ODD symptoms: What is the best model for the organization of these symptoms? Journal of Abnormal Child Psychology. 29:339-349.

108. Ghanizadeh A (2012): Psychometric analysis of the new ADHD DSM-V derived symptoms. BMC psychiatry. 12:1-6.

109. Li Y, Aggen S, Shi S, Gao J, Tao M, Zhang K, et al. (2014): The structure of the symptoms of major depression: exploratory and confirmatory factor analysis in depressed Han Chinese women. Psychological medicine. 44:1391-1401.

110. Miller MW, Wolf EJ, Kilpatrick D, Resnick H, Marx BP, Holowka DW, et al. (2013): The prevalence and latent structure of proposed DSM-5 posttraumatic stress disorder symptoms in US national and veteran samples. Psychological Trauma: Theory, Research, Practice, and Policy. 5:501.

111. Tackett JL, Krueger RF, Iacono WG, McGue M (2005): Symptom-based subfactors of DSMdefined conduct disorder: evidence for etiologic distinctions. Journal of abnormal psychology. 114:483.

112. Janson H, Kjelsberg E (2006): Factor structure and individual patterns of DSM-IV conduct disorder criteria in adolescent psychiatric inpatients. Nordic journal of psychiatry. 60:168-175.

113. Nock MK, Kazdin AE, Hiripi E, Kessler RC (2006): Prevalence, subtypes, and correlates of DSMIV conduct disorder in the National Comorbidity Survey Replication. Psychological medicine. 36:699-710.

114. Olbert CM, Gala GJ, Tupler LA (2014): Quantifying heterogeneity attributable to polythetic diagnostic criteria: theoretical framework and empirical application. Journal of Abnormal Psychology. 123:452. 
medRxiv preprint doi: https://doi.org/10.1101/2021.03.18.21253910; this version posted March 20, 2021. The copyright holder for this preprint (which was not certified by peer review) is the author/funder, who has granted medRxiv a license to display the preprint in perpetuity.

It is made available under a CC-BY-NC 4.0 International license .

Figure 1. Workflow of the current study. Step 1: Creation of a MA map for each experiment, weighted by sample size. Step 2: Pairwise Spearman Rho correlation was performed between every MA map. Step 3: Clustering analysis was performed on the correlation matrix to extract groups of experiments sharing similar MA map. Step 4: ALE meta-analysis was conducted on experiments within each group. Phenotype assessment was then carried out to investigate under/over-representativeness of disorders, sample and task characteristics across identified groups.
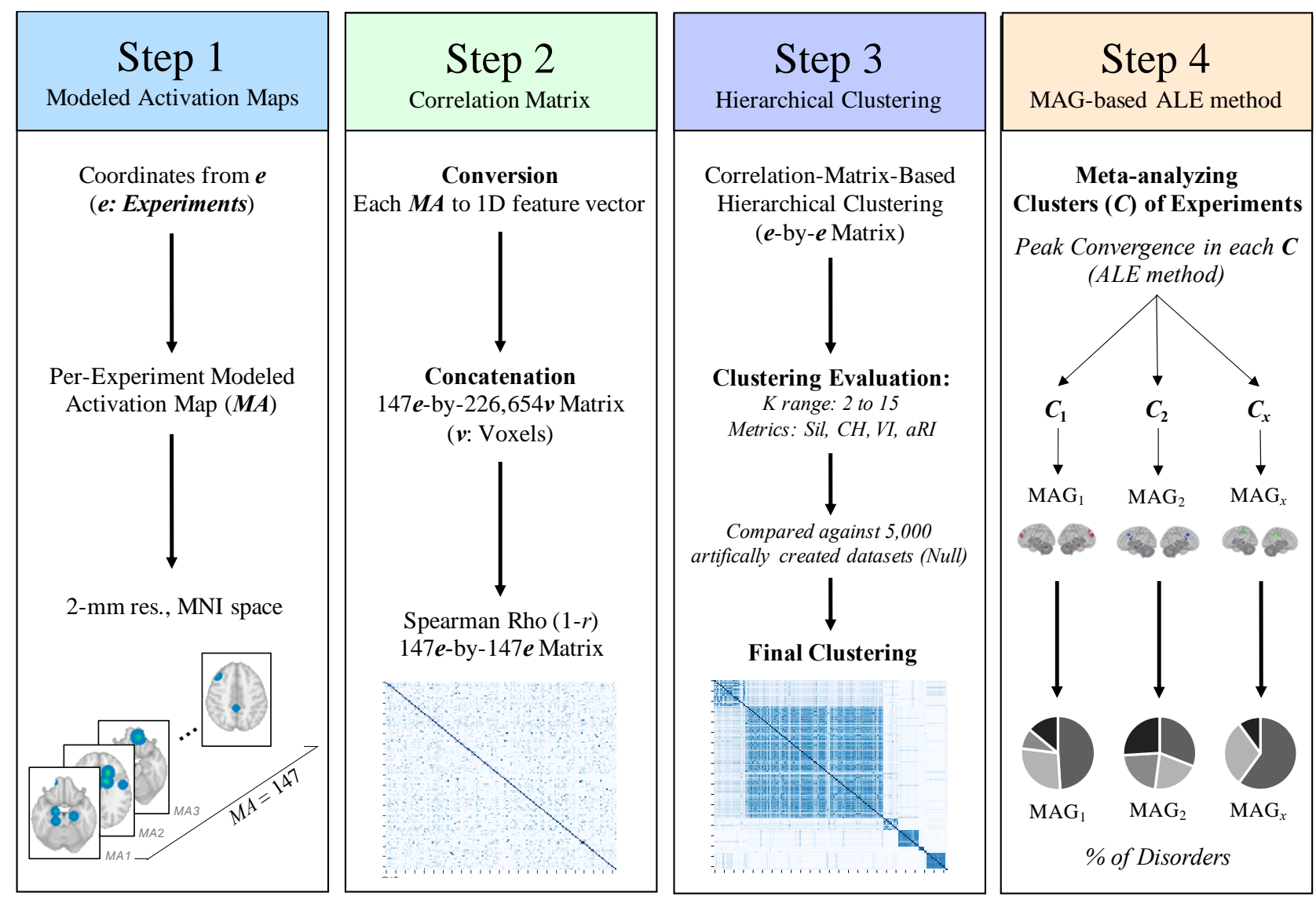
medRxiv preprint doi: https://doi.org/10.1101/2021.03.18.21253910; this version posted March 20, 2021. The copyright holder for this preprint (which was not certified by peer review) is the author/funder, who has granted medRxiv a license to display the preprint in perpetuity.

It is made available under a CC-BY-NC 4.0 International license .

Figure 2. Hierarchical clustering of aberrant activation maps. This dendrogram represents the final hierarchical clustering model which grouped experiment showing similar aberrant activation maps. The 4 significant meta-analytical groupings (MAGs) represented 90.58\% of total sample of experiments: MAG1 $($ green $)=21$ experiments and 577 subjects; MAG2 (black) $=87$ experiments $(1848$ subjects $) ;$ MAG3 = 13 experiments (197 subjects) \& MAG4 (cyan) $=12$ experiments ( 278 subjects).

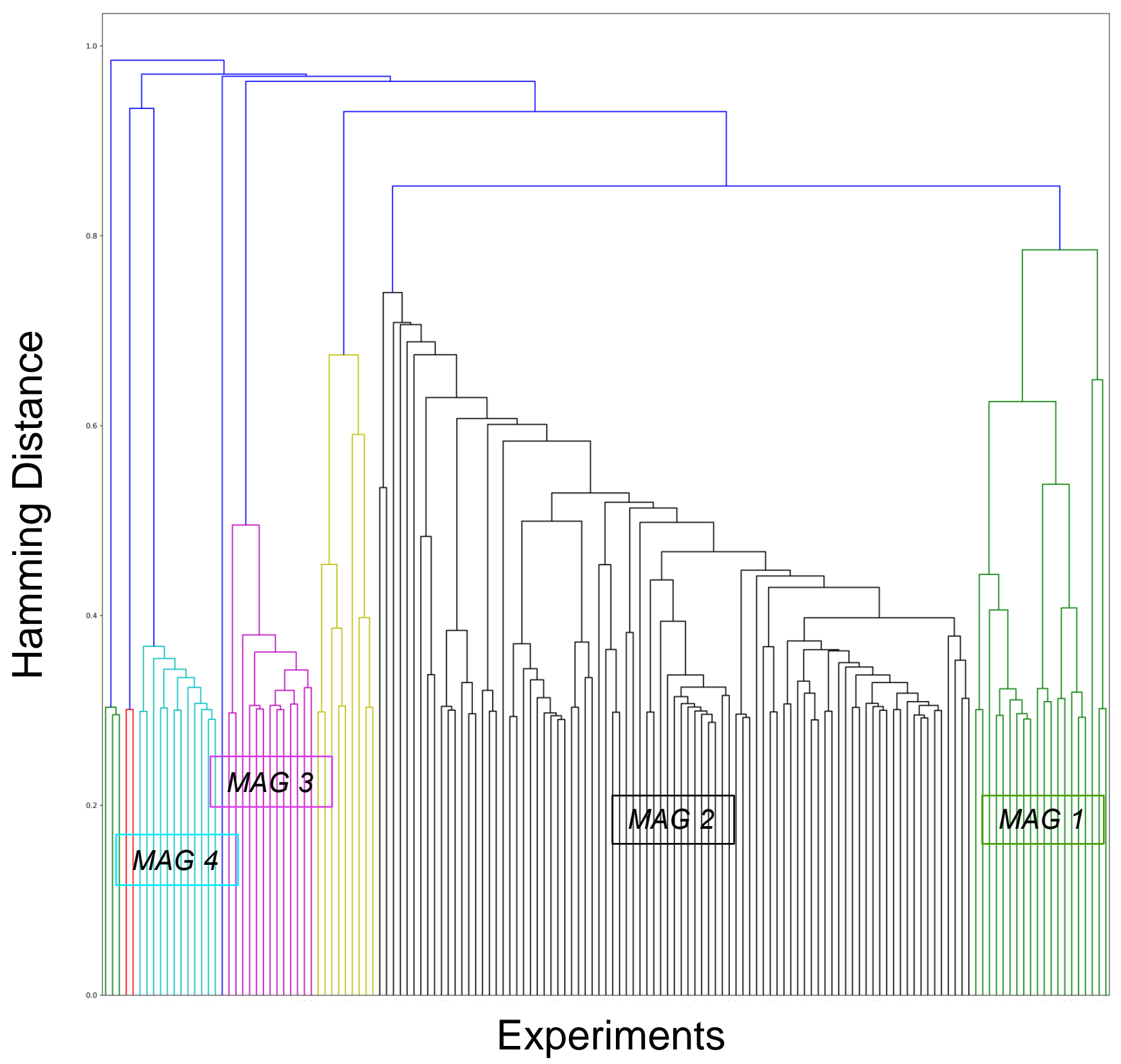


medRxiv preprint doi: https://doi.org/10.1101/2021.03.18.21253910; this version posted March 20, 2021. The copyright holder for this preprint (which was not certified by peer review) is the author/funder, who has granted medRxiv a license to display the preprint in perpetuity.

It is made available under a CC-BY-NC 4.0 International license .

Figure 3. ALE meta-analysis on each significant meta-analytical grouping (MAGs). Images are shown for left hemisphere (lateral), superior view and right hemisphere (lateral) respectively. ALE images were thresholded at $\mathrm{p}<0.001$ at the voxel-level and $\mathrm{pFWE}>0.05$. Word clouds were generated using BrainMap database terms (Behavioral Subdomains \& Paradigm). Font size represents Z-score associated with the whole MAG (all words are significant $\mathrm{p}=0.05$ with Bonferroni correction).

MAG1:

21 exp. (577 cases) 87 exp. (1848 cases)

MAG3:

13 exp. (197 cases)

MAG4: 12 exp. (278 cases)
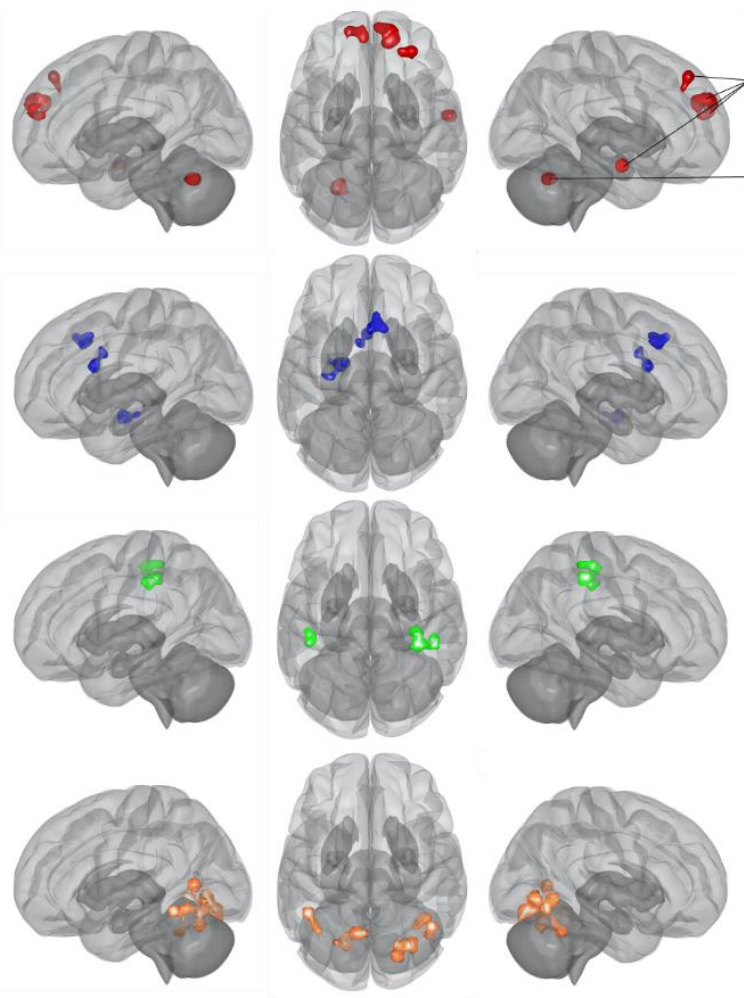

Theory of Mind

Social Cognition Action Execution Finger Tapping/Button Press Recitation/Repetition

Fear Reward Task PassiveViewing Pain Monitor DDscrrmination Inhibition

Face Monitor/Discrimination Positive Emotions Somesthesis Pain Language Semantics Explicit Memory sudnes Attention Reward Reasoning

\section{Action Execution}

Finger Tapping/Button Press

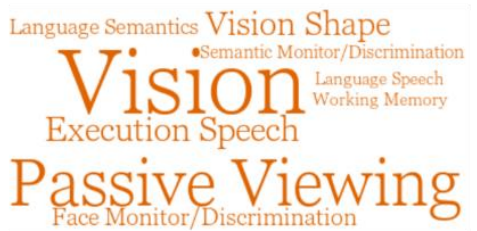


medRxiv preprint doi: https://doi.org/10.1101/2021.03.18.21253910; this version posted March 20, 2021. The copyright holder for this preprint (which was not certified by peer review) is the author/funder, who has granted medRxiv a license to display the preprint in perpetuity.

It is made available under a CC-BY-NC 4.0 International license .

Table 1. ALE meta-analysis results of each significant groups of experiments

\begin{tabular}{|c|c|c|c|c|c|c|c|}
\hline \multirow[t]{2}{*}{ MAGs } & \multirow[t]{2}{*}{ Clusters } & \multirow[t]{2}{*}{ Size $\left(\mathrm{mm}^{3}\right)$} & \multicolumn{3}{|c|}{$\begin{array}{c}\text { MNI } \\
\text { Coordinates }\end{array}$} & \multirow[t]{2}{*}{ ALE } & \multirow[t]{2}{*}{ Cluster Breakdown } \\
\hline & & & $\mathrm{X}$ & $\mathrm{Y}$ & $\mathrm{Z}$ & & \\
\hline \multirow[t]{5}{*}{ MAG1 } & 1 & 2456 & 14 & 46 & 28 & 0.0175 & R dmPFC (rostrodorsal) \\
\hline & 2 & 1152 & -16 & 56 & 22 & 0.0154 & L dmPFC (caudal) \\
\hline & 3 & 1096 & -24 & -60 & -28 & 0.0177 & L Cerebellum (Lobule VI) \\
\hline & 4 & 1048 & 30 & 40 & 46 & 0.0164 & $\mathrm{R}$ dlPFC \\
\hline & 5 & 848 & 58 & -8 & -18 & 0.0216 & R MTG/STG \\
\hline \multirow[t]{3}{*}{ MAG2 } & 1 & 1352 & 8 & 18 & 40 & 0.0243 & R aMCC (Area 32')/pre-SMA \\
\hline & 2 & 1296 & -20 & -10 & -16 & 0.0272 & L Amygdala \\
\hline & 3 & 1040 & -2 & 12 & 22 & 0.0321 & L dACC (Area 24a'-b') \\
\hline \multirow[t]{3}{*}{ MAG3 } & 1 & 976 & 34 & -26 & 52 & 0.0125 & R Pre-/Postcentral gyri (Area 2-3 \& 4p) \\
\hline & 2 & 800 & 46 & -34 & 44 & 0.0133 & R Supramarginal gyrus (Area 2, $\mathrm{PFt}$ ) \\
\hline & 3 & 720 & -42 & -32 & 42 & 0.0112 & L Postcentral gyrus (Area 2, PFt) \\
\hline \multirow[t]{6}{*}{ MAG4 } & 1 & 2336 & 20 & -78 & -12 & 0.0172 & $\mathrm{R}$ Lingual (h0c3v) \\
\hline & 2 & 1224 & -18 & -66 & -24 & 0.0159 & L Cerebellum (Lobule V1) \\
\hline & 3 & 968 & 44 & -58 & -4 & 0.0168 & R pMTG \\
\hline & 4 & 912 & -44 & -48 & -14 & 0.0151 & L pITG \\
\hline & 5 & 736 & -8 & -62 & 6 & 0.0186 & L Calcarine Cortex \\
\hline & 6 & 728 & 40 & -52 & -26 & 0.0155 & R Cerebellum (Lobule VI) \\
\hline
\end{tabular}

Note. $\mathrm{MAG}=$ Meta-analytical Grouping; PFC $=$ Prefrontal Cortex; dmPFC = dorsomedial PFC; dlPFC $=$ dorsolateral PFC; MTG = Middle Temporal Gyrus; STG = Superior Temporal Gyrus; aMCC = anterior MidCingulate Cortex; pre-SMA = pre-supplementary motor area; $\mathrm{dACC}=$ dorsal anterior cingulate cortex; IPL $=$ Inferior Parietal Lobule; SPL $=$ Superior Parietal Lobule; $\mathrm{pMTG}=$ posterior MTG; pITG = posterior ITG. 
Table 2. Characteristics of Experiments across meta-analytical groupings

\begin{tabular}{|c|c|c|c|c|c|c|c|c|c|c|}
\hline \multirow[b]{2}{*}{ Characteristics } & \multicolumn{2}{|c|}{ Total $(n=147)$} & \multicolumn{2}{|c|}{$\begin{array}{l}\text { MAG1 } \\
(\mathrm{k}=21)\end{array}$} & \multicolumn{2}{|c|}{$\begin{array}{l}\text { MAG2 } \\
(\mathrm{k}=87)\end{array}$} & \multicolumn{2}{|c|}{$\begin{array}{l}\text { MAG3 } \\
(\mathrm{k}=13)\end{array}$} & \multicolumn{2}{|c|}{$\begin{array}{l}\text { MAG4 } \\
(\mathrm{k}=12)\end{array}$} \\
\hline & $\mathrm{n}$ & $\%$ & $\mathrm{n}$ & $\%$ & $\mathrm{n}$ & $\%$ & $\mathrm{n}$ & $\%$ & $\mathrm{n}$ & $\%$ \\
\hline \multicolumn{11}{|l|}{ Nosological Categories } \\
\hline ADHD & 79 & $53.7 \%$ & 14 & $66.7 \%$ & 43 & $49.4 \%$ & 8 & $61.5 \%$ & 8 & $66.7 \%$ \\
\hline $\mathrm{CD}$ & 32 & $21.8 \%$ & 4 & $19.0 \%$ & 17 & $19.5 \%$ & 4 & $30.8 \%$ & 3 & $25.0 \%$ \\
\hline ANX & 14 & $9.5 \%$ & 3 & $14.3 \%$ & 9 & $10.3 \%$ & 0 & $0.0 \%$ & 1 & $8.3 \%$ \\
\hline DEP & 22 & $15.0 \%$ & $0^{* \dagger}$ & $0.0 \%$ & $18 \dagger$ & $20.7 \%$ & 1 & $7.7 \%$ & 0 & $0.0 \%$ \\
\hline \multicolumn{11}{|l|}{ Task-contrast Domain } \\
\hline Cognitive & 88 & $59.9 \%$ & 10 & $47.6 \%$ & 53 & $60.9 \%$ & 9 & $69.2 \%$ & 10 & $83.3 \%$ \\
\hline Response Inhibition & 44 & $29.9 \%$ & 7 & $33.3 \%$ & 29 & $33.3 \%$ & 3 & $23.1 \%$ & 4 & $33.3 \%$ \\
\hline Attention & 23 & $15.6 \%$ & 1 & $4.8 \%$ & 13 & $14.9 \%$ & 3 & $23.1 \%$ & 3 & $25.0 \%$ \\
\hline Emotion & 71 & $48.3 \%$ & 12 & $57.1 \%$ & 42 & $48.3 \%$ & $3 *$ & $23.1 \%$ & 5 & $41.7 \%$ \\
\hline Positive & 17 & $11.6 \%$ & $6 * \dagger$ & $28.6 \%$ & $7 *$ & $8.0 \%$ & 0 & $0.0 \%$ & 1 & $8.3 \%$ \\
\hline Negative & 37 & $25.2 \%$ & 4 & $19.0 \%$ & 24 & $27.6 \%$ & 1 & $7.7 \%$ & 2 & $16.7 \%$ \\
\hline Both & 16 & $10.9 \%$ & 2 & $9.5 \%$ & 10 & $11.5 \%$ & 2 & $15.4 \%$ & 2 & $16.7 \%$ \\
\hline \multicolumn{11}{|l|}{ Sample Characteristics } \\
\hline Medication-Naïve & 61 & $41.5 \%$ & $14 \dagger$ & $66.7 \%$ & 40 & $46.0 \%$ & 6 & $46.2 \%$ & 5 & $41.7 \%$ \\
\hline Average Med per sample & - & $26.7 \%$ & - & $35.2 \%$ & - & $26.3 \%$ & - & $19.4 \%$ & - & $20.9 \%$ \\
\hline Mixed Sex Sample & 95 & $64.6 \%$ & 12 & $57.1 \%$ & 60 & $69.0 \%$ & 7 & $53.8 \%$ & 8 & $66.7 \%$ \\
\hline Average Boys per Sample & - & $71.7 \%$ & - & $77.6 \%$ & - & $71.4 \%$ & - & $76.1 \%$ & - & $61.1 \%$ \\
\hline
\end{tabular}

Note. $*$ represent significant difference compared to its base rate (one-tailed $\mathrm{p}<0.05$ ). $\dagger$ represents significant differences between MAGs $(\mathrm{p}<0.05)$ 